\title{
Constructing a Trauma Scoring System from Databases of Road Crash Patients in Philippine Hospitals (2009-2019)
}

\author{
Teodoro J. Herbosa, MD and Jinky Leilanie Lu, MOH, $\mathrm{PhD}^{2}$ \\ ${ }^{1}$ Department of Surgery and Department of Emergency Medicine, College of Medicine and Philippine General Hospital, University of the Philippines Manila \\ ${ }^{2}$ National Institutes of Health, University of the Philippines Manila
}

\begin{abstract}
Introduction. Trauma scoring standardizes the severity of injuries of patients brought to trauma centers and is predictive of the outcome or prognosis among trauma victims. Hence, creating a trauma score allows for proper prioritization as well as proper management of patients in the emergency departments.

Objectives. The objective of the study is to come up with a trauma scoring system that correlates to the probability of survival of a patient using the patient databases in major hospitals in the Philippines representing the three major island groups, Luzon, Visayas, and Mindanao. The study will also compare this proposed trauma scoring system with the gold standard (Revised Trauma Score) developed by Champion in 1989.
\end{abstract}

Methods. The proposed Philippine Trauma Scoring System (PTSS) was based on data from the eight largest tertiary hospitals catering to trauma patients. A total of 40,286 patient charts were reviewed. The proposed trauma scoring system integrates concepts used in the Revised Trauma Score (RTS), with addition of age (from Kampala Trauma Scoring), as well as the Injury Score (based on the number of body parts injured). This proposed scoring system was weighted, using logistic regression to come up with coefficients for the components of the PTSS for a more accurate prediction of patient survival. The Receiver Operating Characteristic (ROC) was used to plot Sensitivity vs. 1-Specificity. In this analysis, ROC was used to evaluate and compare how good the models are in predicting patient recovery.

Results. The components of GCS, RR, SBP, age, and body parts injured were significant predictors of patient outcomes for patients with trauma, specifically the road crash patients in this Philippine study. This study showed that both the PTSS and RTS have a significantly greater area under the curve than the diagonal reference line, which means that both the scoring system have a significant predictive value. The best predictive value, however, comes from the proposed scoring system that is developed from this study in the Philippines. Compared to the gold standard, PTSS Model 1 is a better predictor of outcomes than the gold standard RTS (ROC-AUC $=0.659$ vs. 0.633 ) using only 22,214 valid subject population that contained all the variables needed for the PTSS analysis.

Conclusion. In a developing country like the Philippines, there are limited resources especially in the healthcare setting. Therefore, it is important to lessen errors in triaging which may result in resource waste and a higher risk of adverse outcomes for the patients. Thus, the PTSS developed in this study can be used by Philippine hospitals as it is uniquely based on Filipino patients using a large database representative of the eight largest tertiary hospitals in the Philippines. The proposed PTSS is shown in this study as the best classifier for patient outcome compared to the gold standard - RTS of Champion.

Key Words: Trauma Scoring System, AUC-ROC curve, triage, emergency service, Philippine hospital

Corresponding author: Jinky Leilanie Lu, $\mathrm{MOH}, \mathrm{PhD}$

National Institutes of Health

University of the Philippines Manila

623 Pedro Gil Street, Ermita, Manila 1000, Philippines

Email: jdlu@up.edu.ph 


\section{INTRODUCTION}

Injuries caused by road traffic accidents are the $8^{\text {th }}$ leading cause of death globally, ${ }^{1}$ and the number one cause of death for particularly for children and younger adults aged 5 to 29 years. ${ }^{2}$ This is a great burden since these are the productive years. A recorded 20 to 50 million people suffer from nonfatal injuries due to road crashes; however, the alarming part is that 1.35 million people die due to these accidents every year and the most vulnerable road users were the most affected. ${ }^{1}$ These figures could become worse and may place road injuries as the $5^{\text {th }}$ leading cause of death by 2030 , more especially if these alarming consequences are overlooked. ${ }^{3}$ Thus, in the Philippines, several legislations were passed to decrease mortality related to road traffic injuries.

Triaging is the process of assessing the patients according to their illnesses or injuries and their corresponding degree of severity for injury, outcomes, and resource availability. ${ }^{4}$ The emergence of triage opened doors for delivering quality of care for the patient with lessening trial and errors for the treatment. Moreover, the practical use of triage system is the ability to assess multiple patients for the predictive outcome of their conditions. ${ }^{5}$ Thus, better ways of triaging patients were developed based on scoring systems.

The need for a triage system emerged during the late 60s to early 70s because there was increasing importance in determining the right treatment for the patient at the right time and facility. The development of a scoring system allowed categorizing and problem identification for trauma patients, which significantly helped in the delivery of quality care. ${ }^{5}$ During the mid-1960s, the Abbreviated Injury Scale (AIS) was designed for injuries concerning automotive and aircraft, but later adapted to score traumas that, over the years, had undergone several revisions. ${ }^{6}$ The AIS was the basis for the 1974's Injury Severity Score (ISS) which was the most used trauma scoring system. The ISS is used for multiple trauma patients and is significant in outcome prediction such as mortality and hospital length of stay. In the same year, Glasgow Coma Scale (GCS) was introduced, which assessed the severity of head injury in trauma patients. The GCS score ranges from 3 to 15 with 15 being the normal, 13 to 14 as mild head injury, 9 to 12 as moderate, and finally, a score less than 8 indicating severe head injury. ${ }^{7}$ In 1980, Trauma Score (TS) was developed by Champion et al. $(1989)^{8}$ and was used in triaging patients. The TS evaluated outcomes that mainly used data on circulatory, respiratory, and central nervous systems of the patient; as they reasoned that eaths following trauma were caused by dysfunctions of these systems ${ }^{8}$ However, despite being useful in field triage, lapses were still observed such as difficulties in assessing "retractive respiratory expansion" in addition to the capillary refill and respiratory expansion measurements at nighttime. Underestimation also occurred in the degree of some head trauma patients. These limitations prompted its revision to the Revised Trauma Score (RTS) that mainly used the GCS, systolic blood pressure (SBP), and respiratory rate (RR) in its equation. This gives RTS an edge from TS as the former describes the degree of head injury accurately by 1) incorporating GCS; 2) having increased reliability when predicting patient's care path, and, 3) being easier to use in triaging. ${ }^{8}$ Trauma and Injury Severity Score (TRISS), on the other hand, uses both RTS and ISS, trauma type (blunt or penetrating), and age. ${ }^{9}$ However, the most widely used trauma scoring systems, which are the ISS and the RTS, have lapses especially in calculations in developing countries. Thus, this was one of the objectives for the formulation of the Kampala Trauma Score (KTS) in 1999 (Kobusingye \& Lett, 2000). ${ }^{10}$

The current gold standard for low-income and middleincome countries (LMIC) and high-income countries (HIC) setting in terms of trauma scoring is the RTS. ${ }^{11}$ Some studies have compared the RTS and KTS in LMIC settings. In a study in Western Cape, South Africa, KTS was slightly better in predicting mortality than RTS (ROC area of 0.8731 vs. 0.8625 ). A systematic review also showed that KTS was better in predicting injury severity than RTS. ${ }^{12}$ However, one study showed that in terms of sensitivity, KTS was higher than RTS, but the latter was higher in terms of specificity, diagnostic odds ratio, negative likelihood ratio, and positive likelihood ratio; thus, making RTS slightly better in predicting mortality in the LMIC setting. ${ }^{11}$ On the other hand, several studies showed that TRISS is a better outcome predictor than RTS, KTS, and ISS in the LMIC setting. ${ }^{13-16}$

The Philippines is considered a lower-middle-income country. ${ }^{17}$ The well-being and survival of patients who are victims of traumatic accidents should be the focus of in-hospital care. Thus, the main objective of this study is to develop a trauma scoring system that correlates to the probability of survival of injured patients specifically for the Philippines using a 10-year road traffic injury patient data. This can be used by hospitals in the Philippines since the database consists of Filipino patients.

\section{METHODS}

This study was approved by the Department of Health - Single Joint Research Ethics Board (DOH-SJREB) and UP Manila Research Ethics Board (UPMREB). The study acquired at least 10 years' worth of data from each of the institutions and agencies mentioned. The study population for the hospital data consists of road crash patients rushed to either the emergency departments and/or the trauma department of the included hospitals (Table 1).

\section{The Revised Trauma Scoring System}

There are several multiple injury scoring systems established and used for trauma patient evaluation and studies in developed countries. About 30 years ago, Champion et al. (1989) ${ }^{8}$ introduced the RTS, which has been 
Table 1. Participating hospitals

\begin{tabular}{|c|c|}
\hline Hospital & Classification \\
\hline \multicolumn{2}{|l|}{ Metro Manila } \\
\hline $\begin{array}{l}\text { Philippine General Hospital } \\
\text { Manila }\end{array}$ & $\begin{array}{l}\mathrm{DOH}^{*} 200 \text {-bed, Level } \\
\text { III, medical center and } \\
\text { trauma referral center }\end{array}$ \\
\hline $\begin{array}{l}\text { East Avenue Medical Center } \\
\text { East Avenue, Quezon City }\end{array}$ & $\begin{array}{l}\text { DOH 600-bed, tertiary, } \\
\text { general hospital; training } \\
\text { and teaching center }\end{array}$ \\
\hline $\begin{array}{l}\text { Jose R. Reyes Memorial Medical Center } \\
\text { Manila }\end{array}$ & $\begin{array}{l}\text { DOH 1,500-bed, } \\
\text { tertiary, general hospital; } \\
\text { medical training center }\end{array}$ \\
\hline $\begin{array}{l}\text { Philippine Orthopedic Center } \\
\text { Quezon City }\end{array}$ & $\begin{array}{l}\text { DOH 700-bed, tertiary, } \\
\text { special hospital }\end{array}$ \\
\hline \multicolumn{2}{|l|}{ Cebu } \\
\hline $\begin{array}{l}\text { Talisay District Hospital } \\
\text { San Isidro, City of Talisay, Cebu }\end{array}$ & $\begin{array}{l}\text { DOH regional hospital in } \\
\text { Central Visayas }\end{array}$ \\
\hline $\begin{array}{l}\text { Vicente Sotto Memorial Medical Center } \\
\text { Cebu City }\end{array}$ & $\begin{array}{l}\text { DOH } 1200 \text {-bed, tertiary, } \\
\text { medical center }\end{array}$ \\
\hline \multicolumn{2}{|l|}{ Davao } \\
\hline $\begin{array}{l}\text { Davao Regional Medical Center } \\
\text { Davao Del Norte }\end{array}$ & $\begin{array}{l}\mathrm{DOH} 600 \text {-bed, tertiary, } \\
\text { training hospital }\end{array}$ \\
\hline $\begin{array}{l}\text { Southern Philippines Medical Center } \\
\text { Davao City }\end{array}$ & $\begin{array}{l}\text { DOH 1200-bed, Level III } \\
\text { hospital }\end{array}$ \\
\hline \multicolumn{2}{|l|}{${ }^{*}$ Department of Health } \\
\hline GCS & Code \\
\hline $13-15$ & $10-29$ \\
\hline $76-89$ & $>29$ \\
\hline $50-75$ & $6-9$ \\
\hline $1-49$ & $1-5$ \\
\hline 0 & 0 \\
\hline
\end{tabular}

extensively used to assess outcome or prognosis in trauma patients. The scoring system is a simple and convenient tool for trauma triaging and initial severity survey of patients that do not require high-technology medical examinations or devices for measurements. ${ }^{18}$ This is useful in an emergency department (ED) setting, especially since it involves a fast-paced environment and the movement of patients.

The elements of this physiological score consist of three parameters: GCS, systolic blood pressure (SBP), and respiratory rate (RR); all of which can be assessed easily, quickly, and manually. Each parameter has a corresponding code from 0-4 with assigned specific ranges. After assigning a corresponding code based on the actual values (Table 2), a multiplier shall be applied to code values per parameter to get a weighted coefficient. The weighted coefficient for the three parameters will be added.

RTS is calculated using the following equation:

RTS $=($ GCS code value $\times 0.9368)+($ SBP code value $\times 0.7326)$

$$
+(\text { RR code value } \times 0.2908)
$$

The variables altogether were known to correlate statistically with survival and mortality. A higher RTS is associated with a better chance of survival, while a lower RTS score indicates higher severity of trauma. An RTS score of less than 4 proposed for transfer to a trauma center. ${ }^{8}$ The TRISS combines the indices used in RTS and ISS, thereby accounting for the physiologic and anatomical factors of trauma patients. The physiologic factors are GCS, SBP, and RR. On the other hand, the ISS covers the Abbreviated Injury Score (AIS) of three severely injured body regions: thorax, abdomen, visceral pelvis, head and neck, face, bony pelvis, and extremities, and external structure. In addition to these, age is also considered in TRISS. ${ }^{19}$

\section{Kampala Trauma Score (KTS)}

In developing countries, only a few studies have shown the effectiveness of the different trauma scoring methods. The environment setting, especially with regards to the resources, should be considered in establishing or adapting different trauma scoring methods. Thus, the KTS was developed as a triage tool and intended for use in resource-constrained settings (low- and middle-income countries). It is a good predictor of death or the prognosis of trauma patients.

The KTS has sensitivity and specificity analogous with the RTS, ISS, and TRISS for predicting outcomes retrospectively. ${ }^{10,20}$ The KTS is calculated using the following variables: patient's age, systolic blood pressure (SBP), respiratory rate, AVPU neurologic status (i.e., A - Alert, V responds to Voice, $\mathrm{P}$ - responds to Pain, $\mathrm{U}$ - Unresponsive), and the number of serious injuries attained. Like the RTS, each parameter has a corresponding code with assigned specific values; all code values shall be added. Unlike the RTS, it specifically used AVPU for neurologic assessment than the GCS since this may be more practical to be used developing countries for prompt initial survey (Table 3).

The equation for KTS is shown below:

$\mathrm{KTS}$ score $=$ Age value $+\mathrm{SBP}$ Value $+\mathrm{RR}$ value + Neurologic status value + Serious Injury Value

The authors of the KTS showed that a KTS score of 14 or less was found to increase the patient's likelihood of death by at least three times. ${ }^{21}$ In KTS, neurologic status is measured using AVPU scoring instead of the GCS. The neurologic status is better measured using the GCS than the AVPU. AVPU assessment is just one part of the GCS assessment that corresponds to eye movement.

\section{The Proposed Philippine Trauma Scoring System (PTSS)}

In the proposed PTSS, authors used the GCS rather than the APUV scale in KTS assessment.

The PTSS Model is computed as:

$\mathrm{PTSS}_{1}=\mathrm{SBP}(\mathrm{RTS})+\mathrm{RR}(\mathrm{RTS})+\mathrm{GCS}(\mathrm{RTS})+$ Age $(\mathrm{KTS})+$ Injury Score 
Table 3. Scoring system for Kampala Trauma Score (KTS)

\begin{tabular}{lc}
\multicolumn{1}{c}{ Variables } & Value \\
\hline Age & \\
$5-55$ & 2 \\
$<5$ or $>55$ & 1 \\
\hline SBP & \\
$\quad>89$ & 4 \\
$50-89$ & 3 \\
$1-49$ & 2 \\
Undetectable & 1 \\
\hline$R R$ & \\
$10-29$ & 3 \\
$>30$ & 2 \\
$\quad<9$ & 1 \\
\hline Neurologic Status (AVPU) & \\
Alert & 4 \\
Responds to Verbal Stimuli & 3 \\
Responds to Painful Stimuli & 2 \\
Unresponsive & 1 \\
\hline Serious injuries & 3 \\
None & 2 \\
1 & 1 \\
Equal or greater than 2 & $5-16$ \\
\hline Total Score & \\
\hline
\end{tabular}

The proposed PTSS considers the SBP, RR, and GCS scores following the rules indicated in the RTS, and the scoring for age based on the KTS. The Injury Score in the PTSS is scored $6=$ no injuries, $5=1$ injured body part, ..., $0=6$ injured body part. The higher the PTSS score, the higher the probability to recover.

The proposed PTSS is based on data from the Philippine hospitals consisting of 40,286 patients from the eight largest hospitals in the Philippines over at least ten years. The proposed trauma scoring system integrates concepts used in the RTS, then adding age (from KTS) and an Injury Score which is based on the number of body parts injured. This proposed scoring system is weighted, using logistic regression to come up with coefficients for the components of the PTSS, for a more accurate prediction of patient survival. The Receiver Operating Characteristic (ROC) is the name of the plot of Sensitivity vs. 1-Specificity, and in this analysis, ROC was used to evaluate and compare how good the models are in predicting patient recovery. A total of 22,214 cases were finally included in this analysis as only these have complete information on variables considered in the PTSS.

\section{RESULTS}

Most of the data available were from 2019 and 2018 as these are the readily retrieved hospital data from the participating hospitals, thus representing more than half of the data gathered for the 11 years. There was a total of 40,286 road traffic injury patients from the eight largest hospitals in the Philippines. The majority of the data gathered were from Davao Regional Medical Center (45.5\%), followed
Table 4. Participating hospitals and number of road crash patients data gathered

\begin{tabular}{lrr} 
Hospital & $\begin{array}{r}\text { Patient Data } \\
\text { Gathered (n) }\end{array}$ & Percent \\
\hline Davao Regional Medical Center & 18,333 & 45.5 \\
East Avenue Medical Center & 6,790 & 16.9 \\
Jose R. Reyes Memorial Medical Center & 2,119 & 5.3 \\
Philippine General Hospital & 7,483 & 18.6 \\
Philippine Orthopedic Center & 2,466 & 6.1 \\
Southern Philippines Medical Center & 53 & 0.1 \\
Talisay District Hospital & 2,439 & 6.1 \\
Vicente Sotto Memorial Medical Center & 603 & 1.4 \\
Missing & 2 & 0.0 \\
\hline Total & 40,286 & 100.0 \\
\hline
\end{tabular}

Table 5. Distribution of socio-demographic characteristics of road crash victims brought in the major tertiary hospitals in the Philippines

\begin{tabular}{|c|c|c|}
\hline Variables & $\begin{array}{l}\text { Frequency } \\
\text { (n) }\end{array}$ & $\begin{array}{l}\text { Percentage } \\
\text { (\%) }\end{array}$ \\
\hline \multicolumn{3}{|l|}{ Age } \\
\hline 9 and below & 3,557 & 8.9 \\
\hline 10 to 19 & 5,686 & 14.2 \\
\hline 20 to 29 & 11,352 & 28.3 \\
\hline 30 to 39 & 7,856 & 19.6 \\
\hline 40 to 49 & 5,303 & 13.2 \\
\hline 50 to 59 & 3568 & 8.9 \\
\hline 60 to 69 & 1880 & 4.7 \\
\hline 70 and above & 857 & 2.1 \\
\hline \multicolumn{3}{|l|}{ Sex } \\
\hline Male & 29,884 & 77.104 \\
\hline Female & 8,874 & 22.896 \\
\hline \multicolumn{3}{|l|}{ Marital Status } \\
\hline Single & 18,497 & 62.564 \\
\hline Married & 11,068 & 37.436 \\
\hline \multicolumn{3}{|l|}{ Context of Mechanism of Injury } \\
\hline Slipped/Lost balance/Lost control/Slid & 3,885 & 40.865 \\
\hline Fell off/Thrown off & 2,935 & 30.872 \\
\hline Avoided pedestrian & 123 & 1.294 \\
\hline Avoided animal & 122 & 1.283 \\
\hline Avoided object & 58 & 0.610 \\
\hline Burst tire & 30 & 0.316 \\
\hline Swerved & 224 & 2.356 \\
\hline Others & 2,130 & 22.405 \\
\hline \multicolumn{3}{|l|}{ Victim Type } \\
\hline Driver & 10,019 & 58.502 \\
\hline Passenger & 3,265 & 19.065 \\
\hline Pedestrian & 3,842 & 22.434 \\
\hline
\end{tabular}

by the Philippine General Hospital's Integrated Surgical Information System (18.6\%), then East Avenue Medical Center (16.9\%), while the rest were from other participating hospitals (Table 4).

Table 5 shows the socio-demographics of the road crash patients from the hospitals. Those within the productive 
age groups were the most affected. Road users aged 20 to 29 years comprised the majority $(28.3 \%)$ of the total road crash victims, followed by those aged 30 to 39 (19.6\%). The least involved in road crashes were those aged 60 years and above $(6.8 \%)$. The mean age of patients admitted to participating hospitals was 31.6 years (SD 16.67). The distribution of age was bimodal, with the first peak for 5-year-olds, and the highest peak for 22-year-olds. Males (77.10\%) were primarily affected than females (22.9\%).

Single patients constituted more than half (62.7\%) of the total road crash victims. Majority (58.5\%) of the reported victim type were drivers, followed by pedestrians $(22.4 \%)$ and passengers (19.1\%). The most common context of the mechanism of injury of the road crash patients was slipped/ lost balance/lost control/slid (40.9\%), followed by fell off/ thrown off (30.9\%), and others (22.4\%).

Majority of the patients were classified as charity (95.5\%) patients or consulted as emergency cases (93.7\%) (Table 6).

In addition, majority of the road crash patients had normal vital signs: $\mathrm{BP}(57.6 \%), \mathrm{SBP}(67.1 \%), \mathrm{DBP}(75.8 \%)$, and HR (79.3\%). Almost half of the patients (42.2\%) exhibited abnormally high RR.

The most common injury among road crash patients was external injury $(73.7 \%)$. This was followed by injuries to the extremity (53.4\%), head and neck (41.1\%), face (23.2\%), and chest (18.4\%). Majority of the patients did not suffer brain injury (79.9\%) compared to $7.2 \%$ who suffered severe brain injury. Multiple injuries were prevalent among $42.2 \%$ of the patients. Majority of the patients also suffered from blunt trauma to the head $(78.3 \%)$, face $(53.5 \%)$, chest $(76.0 \%)$, abdomen (85.7\%), extremity (60.0\%), and externals (65.7\%).

Majority (74.4\%) recovered or improved while $15.3 \%$ of the patients died.

\section{Proposed PTSS Patient Road Crash Data}

Two scoring systems are presented here. The first uses the RTS of Champion et al. (1989) ${ }^{8}$ as cited above. The second is the proposed PTSS combining the RTS and KTS. The KTS cannot be calculated in this study since there was no neurologic status variables used in KTS.

Table 6. Distribution of hospital data of road crash patients admitted in the major tertiary hospitals in the Philippines

\begin{tabular}{|c|c|c|c|}
\hline Variables & Variable Levels & Frequency (N) & Percentage (\%) \\
\hline \multirow{2}{*}{$\begin{array}{l}\text { Patient } \\
\text { Classification }\end{array}$} & Charity & 33,611 & 95.474 \\
\hline & Paying & 1,593 & 4.525 \\
\hline \multirow[t]{2}{*}{ Consult Type } & Emergency & 34,265 & 93.653 \\
\hline & Elective & 2,322 & 6.346 \\
\hline \multirow{2}{*}{$\begin{array}{l}\text { Blood } \\
\text { Pressure (BP) }\end{array}$} & Within Normal Ranges & 16,178 & 57.618 \\
\hline & Abnormal & 11,900 & 42.381 \\
\hline \multirow[t]{3}{*}{ Systolic BP } & Abnormally Low & 327 & 1.166 \\
\hline & Normal & 18,817 & 67.129 \\
\hline & Abnormally High & 8,887 & 31.704 \\
\hline \multirow[t]{3}{*}{ Diastolic BP } & Abnormally Low & 1,129 & 4.026 \\
\hline & Normal & 21,247 & 75.771 \\
\hline & Abnormally High & 5,665 & 20.202 \\
\hline \multirow{3}{*}{$\begin{array}{l}\text { Heart Rate } \\
\text { (HR) }\end{array}$} & Abnormally Low & 493 & 1.749 \\
\hline & Normal & 22,331 & 79.258 \\
\hline & Abnormally High & 5,351 & 18.990 \\
\hline \multirow{3}{*}{$\begin{array}{l}\text { Respiratory } \\
\text { Rate (RR) }\end{array}$} & Abnormally Low & 227 & 0.816 \\
\hline & Normal & 11,738 & 42.236 \\
\hline & Abnormally High & 15,826 & 56.946 \\
\hline \multirow{4}{*}{$\begin{array}{l}\text { Glasgow Coma } \\
\text { Score (GCS) }\end{array}$} & No Brain Injury & 24,031 & 79.879 \\
\hline & Minimal Brain Injury & 2,541 & 8.446 \\
\hline & Moderate Brain Injury & 1,346 & 4.474 \\
\hline & Severe Brain Injury & 2,166 & 7.199 \\
\hline \multirow{2}{*}{$\begin{array}{l}\text { Head and } \\
\text { Neck Injury }\end{array}$} & No & 14,533 & 58.891 \\
\hline & Yes & 10,145 & 41.109 \\
\hline \multirow[t]{2}{*}{ Face Injury } & No & 14,834 & 76.804 \\
\hline & Yes & 4,480 & 23.196 \\
\hline \multirow[t]{2}{*}{ Chest Injury } & No & 15,611 & 81.635 \\
\hline & Yes & 3,512 & 18.365 \\
\hline \multirow{2}{*}{$\begin{array}{l}\text { Abdomen } \\
\text { Injury }\end{array}$} & No & 16,181 & 89.596 \\
\hline & Yes & 1,879 & 10.404 \\
\hline
\end{tabular}

\begin{tabular}{|c|c|c|c|}
\hline Variables & Variable Levels & Frequency (N) & Percentage (\%) \\
\hline \multirow{2}{*}{$\begin{array}{l}\text { Extremity } \\
\text { Injury }\end{array}$} & No & 11,394 & 46.563 \\
\hline & Yes & 13,076 & 53.437 \\
\hline \multirow[t]{2}{*}{ External Injury } & No & 6,388 & 26.286 \\
\hline & Yes & 17,914 & 73.714 \\
\hline \multirow{2}{*}{$\begin{array}{l}\text { Head Injury } \\
\text { Type }\end{array}$} & Blunt & 6,980 & 78.313 \\
\hline & Penetrating & 1,933 & 21.687 \\
\hline \multirow{2}{*}{$\begin{array}{l}\text { Face Injury } \\
\text { Type }\end{array}$} & Blunt & 1,702 & 53.455 \\
\hline & Penetrating & 1,482 & 46.545 \\
\hline \multirow{2}{*}{$\begin{array}{l}\text { Chest Injury } \\
\text { Type }\end{array}$} & Blunt & 2,122 & 76.003 \\
\hline & Penetrating & 670 & 23.997 \\
\hline \multirow{2}{*}{$\begin{array}{l}\text { Abdomen } \\
\text { Injury Type }\end{array}$} & Blunt & 1,294 & 85.695 \\
\hline & Penetrating & 216 & 14.305 \\
\hline \multirow{2}{*}{$\begin{array}{l}\text { Extremity } \\
\text { Injury Type }\end{array}$} & Blunt & 7,255 & 60.033 \\
\hline & Penetrating & 4,830 & 39.967 \\
\hline \multirow{2}{*}{$\begin{array}{l}\text { External } \\
\text { Injury Type }\end{array}$} & Blunt & 10,232 & 65.716 \\
\hline & Penetrating & 5,338 & 34.284 \\
\hline \multirow{7}{*}{$\begin{array}{l}\text { Sum of Body } \\
\text { Parts Injured }\end{array}$} & 0 body part injured & 1,098 & 3.165269 \\
\hline & 1 body part injured & 20,316 & 58.56612 \\
\hline & 2 body parts injured & 9,686 & 27.9224 \\
\hline & 3 body parts injured & 2,879 & 8.299461 \\
\hline & 4 body parts injured & 618 & 1.781545 \\
\hline & 5 body parts injured & 78 & 0.224855 \\
\hline & 6 body parts injured & 14 & 0.040359 \\
\hline \multirow{2}{*}{$\begin{array}{l}\text { Multiple } \\
\text { Injuries }\end{array}$} & No & 17,995 & 57.781 \\
\hline & Yes & 13,148 & 42.218 \\
\hline \multirow{6}{*}{$\begin{array}{l}\text { Patient } \\
\text { Outcomes }\end{array}$} & Recovered/Improved & 24,974 & 74.493 \\
\hline & Died & 5,128 & 15.296 \\
\hline & Unchanged & 439 & 1.309 \\
\hline & Transferred & 772 & 2.302 \\
\hline & HAMA & 1,994 & 5.947 \\
\hline & Absconded & 218 & 0.650 \\
\hline
\end{tabular}




\section{Revised Trauma Score - the Gold Standard}

Data from 2009 to 2019 showed that the severity of injuries through RTS fluctuated but generally in a decreasing trend. The mean RTS score from 2009 decreased from 7.41 to 7.31 thereby implying that injury severity from road crashes may have become more serious over the years. This indicates decreased recovery possibilities for these patients (Figure 1).

Using the RTS formula, the scores generated from the Philippine hospital database are shown in Table 7. Table 8 shows the proportion of recoveries using the RTS formula.

There are 25,020 samples used in this formula. The ROC-AUC for the RTS scores from the Philippine hospital database is shown in Table 9.

Based on the AUC-ROC curve for the RTS formula, the RTS was above the reference line set at 0.5 or $50 \%$ predictability (Figure 2).

\section{Proposed PTSS Model}

For the proposed PTSS model using the Philippine hospital database, the coefficients were derived using logistic regression on the dependent variable:

$$
y=\left\{\frac{1 \text { if patient has recovered }}{0 \text { if other patient outcome }}\right.
$$

The model considered unchanged patient outcomes, as well as other outcomes such as "discharged," "HAMA," "transferred," and others. The model also maximized the use of the database due to less exclusion of data. 22,214 patient data were analyzed in modeling the first variant of the PTSS model (Table 10).

The resulting equation is as follows:

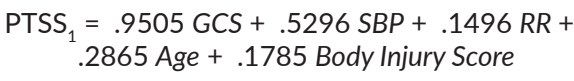

Table 7. Frequency distribution of RTS components based on Score

\begin{tabular}{lrrrrr} 
& \multicolumn{5}{c}{ Score } \\
\cline { 2 - 6 } & $\mathbf{0}$ & \multicolumn{1}{c}{$\mathbf{1}$} & \multicolumn{1}{c}{$\mathbf{3}$} & \multicolumn{1}{c}{$\mathbf{4}$} \\
\hline Glasgow Coma Score & 460 & 753 & 954 & 1346 & 26558 \\
Systolic Blood Pressure & 191 & 29 & 310 & 448 & 30114 \\
Respiratory Rate & 658 & 9 & 11 & 28389 & 1623 \\
\hline
\end{tabular}

Table 8. Proportion of recoveries by RTS Score

\begin{tabular}{lrrrc}
\multicolumn{1}{c}{ RTS Score } & Recovered & Died & Total & Recoveries (\%) \\
\hline Less than 1 & 1 & 35 & 36 & 2.78 \\
1 to 1.99 & 1 & 44 & 45 & 2.22 \\
2 to 2.99 & 9 & 126 & 135 & 6.67 \\
3 to 3.99 & 38 & 242 & 280 & 13.57 \\
4 to 4.99 & 141 & 331 & 472 & 29.87 \\
5 to 5.99 & 375 & 368 & 743 & 50.47 \\
6 to 6.99 & 1255 & 238 & 1493 & 84.06 \\
7 and above & 18418 & 802 & 19220 & 95.83 \\
\hline
\end{tabular}

Table 9. ROC-AUC for RTS Score $(n=25,020)$

\begin{tabular}{ccccc}
\multirow{2}{*}{ Area } & Std. & Asymptotic & \multicolumn{2}{c}{ Asymptotic $95 \% \mathrm{Cl}$} \\
\cline { 4 - 5 } & Error & Sig. & Lower Bound & Upper Bound \\
\hline 0.639 & 0.005 & 0.000 & 0.630 & 0.649 \\
\hline
\end{tabular}

Based on the coefficients, GCS score contributed $46.57 \%$ to the trauma scoring system, SBP contributed $25.95 \%$, RR contributed $7.33 \%$, age contributed $7.01 \%$, and the Body Injury Score or the number of body parts injured contributed $13.12 \%$.

For PTSS score 7 and above, the proportion of recovered was more than 95\%. It is notable that for the PTSS model, most of the data were concentrated on above 7 scores (Table 11).

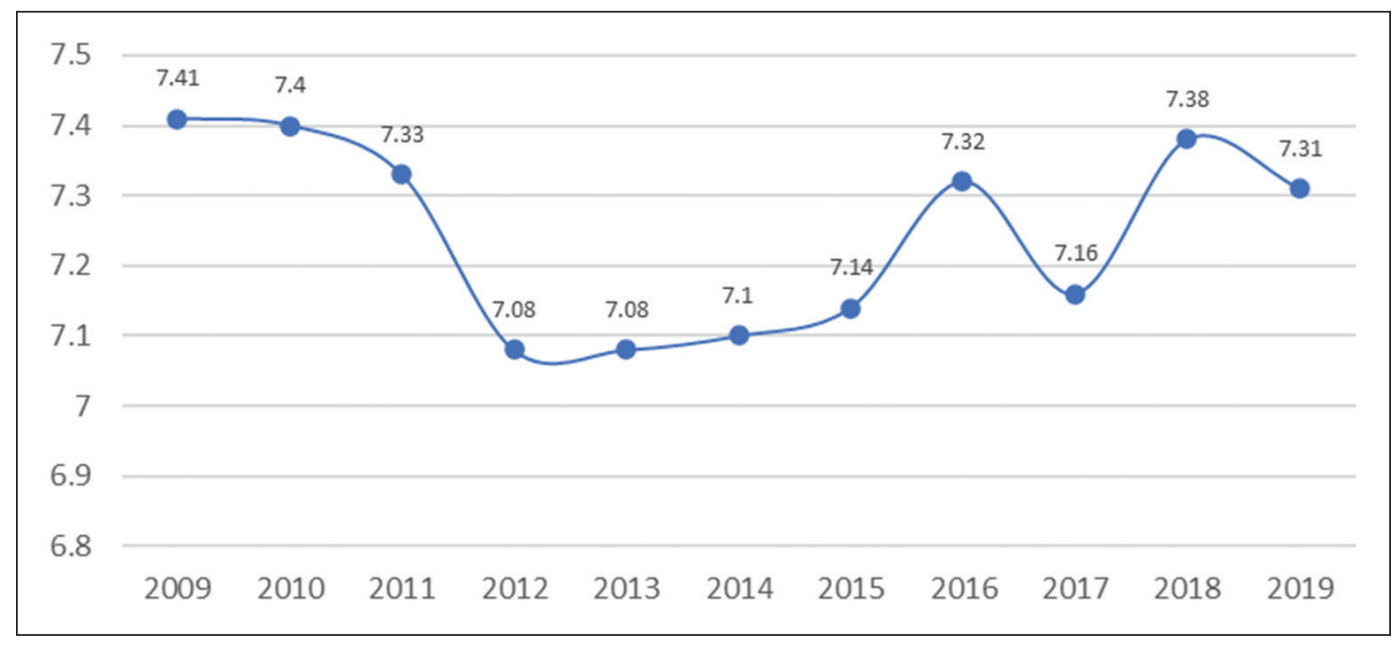

Figure 1. Mean RTS Score of road crash victims brought to the participating major tertiary hospitals in the Philippines from 2009 to 2019. 
Table 10. Logistic Regression for PTSS Model

\begin{tabular}{lcccccc} 
& B & S.E. & Sig. & Exp(B) & \multicolumn{2}{c}{$95 \%$ Cl for EXP(B) } \\
\cline { 6 - 7 } & & & & & Lower Bound & Upper Bound \\
GCS & 0.9505 & 0.0255 & 0.0000 & 2.5869 & 2.4610 & 2.7193 \\
SBP & 0.5296 & 0.0542 & 0.0000 & 1.6982 & 1.5272 & 1.8885 \\
RR & 0.1496 & 0.0371 & 0.0001 & 1.1614 & 1.0800 & 1.2489 \\
Age & 0.2865 & 0.0526 & 0.0000 & 1.3317 & 1.2014 & 1.4763 \\
Body Injury Score & 0.1785 & 0.0221 & 0.0000 & 1.1955 & 1.1447 & 1.2484 \\
Constant & -5.9229 & 0.2781 & 0.0000 & 0.0027 & & \\
\hline
\end{tabular}

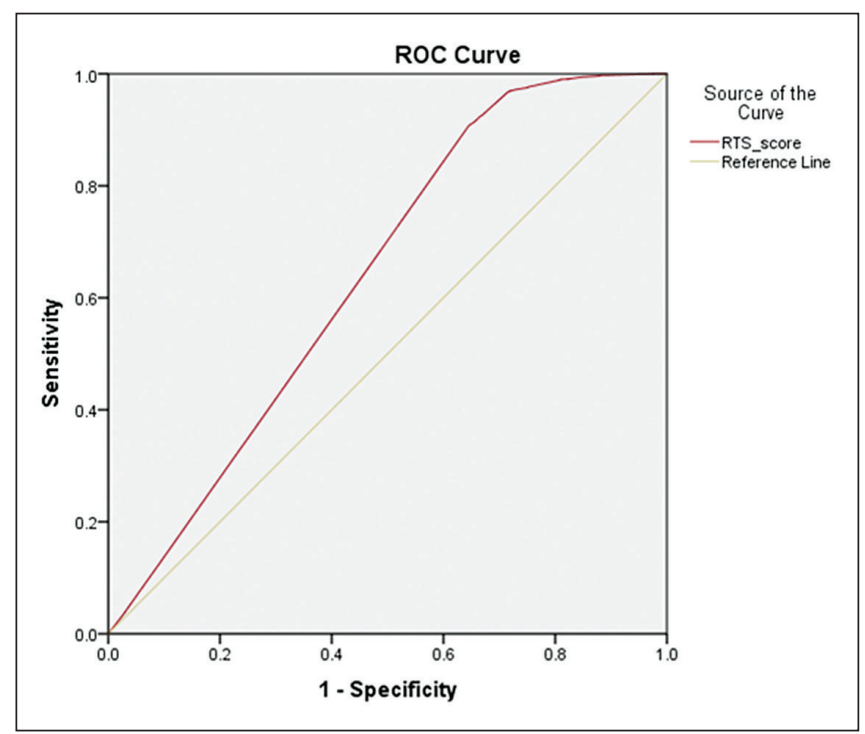

Figure 2. ROC-AUC analysis of RTS.

Table 11. Proportion of Recovery by PTSS Model Scores

\begin{tabular}{lrrrc} 
PTSS Model Score & Recovered & Died & Total & $\begin{array}{c}\text { Proportion of } \\
\text { Recovered }\end{array}$ \\
\hline Less than 3 & 2 & 88 & 90 & $2.22 \%$ \\
3 to 3.99 & 15 & 158 & 173 & $8.67 \%$ \\
4 to 4.99 & 63 & 334 & 397 & $15.87 \%$ \\
5 to 5.99 & 335 & 337 & 672 & $49.85 \%$ \\
6 to 6.99 & 981 & 226 & 1207 & $81.28 \%$ \\
7 and above & 16548 & 737 & 17285 & $95.74 \%$ \\
\hline
\end{tabular}

Table 12. ROC-AUC analysis of RTS and PTSS Model

\begin{tabular}{|c|c|c|c|c|c|}
\hline \multirow{2}{*}{$\begin{array}{l}\text { Test Result } \\
\text { Variable/s }\end{array}$} & \multirow[b]{2}{*}{ Area } & \multirow{2}{*}{$\begin{array}{l}\text { Std. } \\
\text { Error }\end{array}$} & \multirow{2}{*}{$\begin{array}{l}\text { Asymptotic } \\
\text { Sig.B. }\end{array}$} & \multicolumn{2}{|c|}{ Asymptotic $95 \% \mathrm{Cl}$} \\
\hline & & & & $\begin{array}{l}\text { Lower } \\
\text { Bound }\end{array}$ & $\begin{array}{l}\text { Upper } \\
\text { Bound }\end{array}$ \\
\hline RTS score & 0.633 & 0.005 & 0.000 & 0.622 & 0.643 \\
\hline PTSS model & 0.659 & 0.005 & 0.000 & 0.649 & 0.669 \\
\hline
\end{tabular}

Using the ROC-AUC analysis, the PTSS model (AUC, 0.659) performed better than the RTS (AUC, 0.633) $(\mathrm{N}=$ 22,214 samples) (Table 12). Both curves were significantly better than the reference line, which suggests that both can distinguish between patient outcomes (Figure 3).

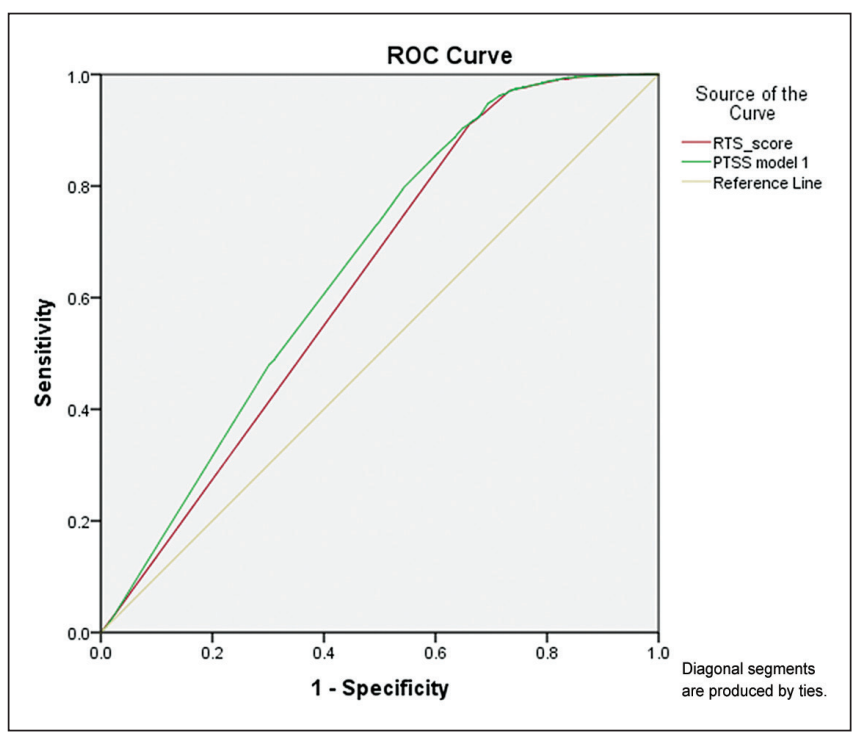

Figure 3. ROC-AUC analysis of RTS and PTSS Model.

\section{DISCUSSION}

This study showed that the PTSS model had an AUC of 0.659 while RTS had an AUC of 0.633. Within these two models, the PTSS model had the higher AUC, suggesting that it was a better classifier.

\section{Glasgow Coma Scale}

The PTSS used GCS scores to predict the severity of head injury. The development of GCS in 1974 established the importance of neurological function in triage (Wisner, 1992). ${ }^{5}$ The GCS alone can predict mortality, ${ }^{22}$ and a low GCS score was associated with increased mortality as one study had indicated. ${ }^{23}$ This was also the same in LMIC patients (Amorim, et al., 2020) ${ }^{24}$ and the specific component of GCS increased the risk for mortality especially when the motor component was less than or equal to the score of $3 .{ }^{24}$

Moreover, brain injury was one major reason for the increased mortality and morbidity in younger patients. ${ }^{25}$ In a study with subjects aged 6 years and younger, a lower GCS score was associated with increased mortality (Huang, Huang, Hsieh, Li, \& Chiu, 2019). ${ }^{25}$ Increased mortality in patients with low GCS scores may be associated with 
decreased awareness and coordination during treatment; therefore, recovery is less likely as compared to patients with mild- to moderate-grade GCS. ${ }^{23}$

The KTS formula incorporates AVPU scoring instead of GCS. The AVPU scale is mostly used in general wards as an early warning score for head injuries. ${ }^{26}$ However, when compared to GCS, AVPU was inferior in predicting mortality. ${ }^{26}$ In pediatric patients, the use of AVPU is most beneficial in infants; however, this is not the case for older children because GCS is primarily used in them. Due to the wide variability of V/P score in GCS, AVPU is not for long-term monitoring of neurological status, although it is highly beneficial for an initial assessment. Even though AVPU is simple to use, there are corresponding GCS scores that are equivalent to AVPU. ${ }^{27}$ The AVPU has a tendency to under-triage patients as well. ${ }^{7}$

Therefore, it is better to incorporate GCS than AVPU as opposed to the KTS that used the latter in assessing the neurological status of patients. The former may accurately score/describe the corresponding brain injury more than the AVPU. After all, one study showed that RTS performed slightly better than KTS in mortality prediction. ${ }^{11}$ One of the reasons why Trauma Scoring was revised to RTS was to address the underestimation of patients with brain injury. ${ }^{8}$

\section{Systolic Blood Pressure and Respiratory Rate}

One of the objectives in revising the trauma score was to adopt SBP and RR values as these vital signs are associated with the probability of survival of the patient. ${ }^{8}$ Both RTS and KTS incorporate the vital signs of SBP and RR in their formula. This is also the same for the two models of PTSS. Several studies associated SBP with mortality. In a study among Chinese adults, either a lower $(<100 \mathrm{mmHg})$ or higher $\left(\geq 120 \mathrm{mmHg}\right.$ ) SBP increased the risk for mortality. ${ }^{28}$ Among older people aged $\geq 65$ years old and above, increased mortality risk was observed for adults with lower $<110 \mathrm{mmHg}$ and high > $139 \mathrm{mmHg}$ SBP (Shih, et al., 2016). ${ }^{29}$ Moreover, among patients with thoracic injuries, low $\mathrm{SBP}(<90 \mathrm{mmHg})$ is a highly specific tool for physiologic derangement. ${ }^{30}$ These studies suggest that SBP could be a predictor of mortality as well. In this study, the majority of the patients in the hospital database belong to the group that had normal SBP (67.13\%) followed by abnormally high SBP (31.7\%), with the least having abnormally low SBP (1.2\%).

Several studies also established the importance of RR in predicting the prognosis of patients. An earlier study that also compared RR and BP showed that RR identifies highrisk patients better than the latter. ${ }^{31}$ For the recent body of knowledge, in a study among emergency patients, those with RR of over 30 had increased risk for ICU admission and 30day mortality. ${ }^{32}$ In trauma patients, tachypnea, which was found to be under triaged in the level 3 criteria of the study (mechanism of injury), was associated with suspected thoracic injury. A high RR was also associated with an increased risk of mortality among patients with COVID-19.33 The increased rate of $\mathrm{RR}$ is due to the body trying to maintain the normal amounts of oxygen in the tissues. ${ }^{34}$ On the other hand, an RR of less than 8 also increased the odds of death within a day by $18.1 \%$ in comparison to a normal RR defined as $8-25.32$

Comparing models 1 and 2 of the PTSS, the RR contributes less than the SBP and GCS scores. The RR only contributes $7.33 \%$ for both of the PTSS models, and this is similar to RTS. ${ }^{35}$ This is due to the low reproductive rate of RR when measured clinically and due to its wide normal range. More so, ventilation and/or oxygenation disorders among trauma patients are caused by pain and psychological stress and does not correlate entirely with RR; thereby making the latter a debatable issue in RTS.., 35

Vital signs are important physiologic factors that give an overview of the patient's condition ${ }^{31}$ and should be accurately monitored. The inclusion of SBP and RR in the RTS and the proposed PTSS are important in improving the triaging of trauma patients.

\section{Age}

Several studies associated age with mortality. It was found that older people have increased mortality, ${ }^{32}$ and that among severe trauma patients, mortality increased by $29 \%$ and $40 \%$ in patients aged $75-84$ and $\geq 85$ years. ${ }^{36}$ This is also the same case with decreasing age. ${ }^{37}$ The same study also found that road traffic accidents among children aged less than 1 year had a mortality rate of $15 \% \cdot{ }^{37}$ For older patients, a decreased ability to repair damage and recovery rate ${ }^{38}$ may be associated with increased mortality. ${ }^{39}$ Younger children are vulnerable because they are still growing and are not fully developed in terms of physiological functions. In this study, the older age group which was composed of 60-yearolds and older accounted for about $6.8 \%$ of the total patients recorded while patients whose ages were 9 years and below were at $8.9 \%$. The majority of the patients involved in a road crash from Philippine hospitals were from 20 to 29 years of age $(28.3 \%)$ followed by 30 to $39(19.6 \%)$ years.

However, age alone is not a good predictor of mortality. ${ }^{36,40}$ The inclusion of age in trauma scoring may further help in accurate triaging. Thus, one of the objectives of the KTS was to make it applicable to all ages especially in a setting where pediatric hospitals are limited such as LMICs, ${ }^{10}$ which is one limitation of RTS as the variable is not included in the RTS formula. This is also the same principle why age is added in the formulation of the two models of PTSS for the Philippine setting.

\section{Body Parts Injured}

In children who are trauma patients, the most common body part injured was the head and neck. ${ }^{37,41,42}$ Head injuries and hemorrhage were also the leading cause of death in adult trauma patients in a study by Oyeniyi, et al. (2017). ${ }^{43}$ The determination of head injuries through GCS scoring is the strength of RTS; however, the latter has a tendency of 
under-triaging the severity of body injuries (Feldhaus, et al., $2020)^{12}$ as the formula did not include that specific variable.

While RTS is a good trauma scoring system for multiple injured trauma patients and traumatic brain injury patients for mortality predictions. ${ }^{35,44}$ it underestimates the injury severity. It was not a good predictor for patients with blunt or penetrating traumas ${ }^{12,44}$ because RTS does not account for body parts injured. This may be due to the large GCS constant in the RTS which can affect the values. For instance, patients with traumatic brain injuries may be given a low GCS score while those with penetrating and blunt traumas could be given higher GCS scores especially if they do not have brain trauma. Thus, it is important to determine the mechanism of injury. ${ }^{44}$ This was the reason why the proposed PTSS has the variable for body parts injured as to account for the latter because different body parts are also affected in the case of traumatic accidents as such as head, foot, face, and forearm are sites of body injuries in the case of motorcycle trauma patients. ${ }^{42}$ The body parts injured variable is similar to that of the KTS, which is a better determinant of injury severity than RTS. ${ }^{12}$ In this study, more than half of the patients suffered from external (73.7\%) and extremity injury (53.4\%) while two-thirds of the patients reported head and neck injury (41.1\%).

Contrasting results on the effectiveness of RTS and KTS in predicting mortality were published. Some studies claimed that KTS is better in predicting mortality especially in the LMIC setting, ${ }^{13,16}$ while other studies showed that RTS performed better. ${ }^{11,45}$ Nevertheless, the two models of the PTSS were comparable in performance in survival prediction among the patients in this study and are also both better than RTS.

RTS and KTS have their limitations. For one, RTS was not age-specific and has a tendency of underestimating body injuries whereas KTS uses AVPU, which has a tendency of under-triaging patients and is inferior to GCS for predicting mortality among patients with head trauma. The proposed PTSS combines the principles of RTS and KTS, and hence, addresses both their limitations. It is for this rationale that the proposed Philippine Trauma Scoring is superior to the RTS based on the ROC-AUC.

\section{CONCLUSION}

The proposed PTSS was shown in this study as a better classifier than the gold standard RTS in predicting patient outcomes, particularly trauma victims. The components of GCS, RR, SBP, age, and body parts injured are significant predictors of patient outcomes for trauma patients, specifically the road crash patients in this Philippine study.

We constructed a proposed trauma scoring system (PTSS) that outperformed RTS in predicting survival outcomes of patients in the Philippine hospitals. An accurate trauma scoring system that is based on Philippine demographic data is a good tool for accurately determining high-risk patients needing prompt medical management or referral to other trauma centers to lessen negative outcomes for road crashes and trauma patients.

With tertiary hospitals having limited resources and developing countries having the highest trauma cases, it is important to accurately determine high-risk patients for prompt quality care, allocation of hospital resources, and/or referral. Over and under-triaging may increase the risk of adverse outcomes for the patient. Thus, it is hoped that the proposed model will greatly help in improving triaging and trauma scoring in a developing country like the Philippines, as was KTS was developed to consider the resource context of low-middle-income countries.

\section{Statement of Authorship}

Both authors contributed in the conceptualization of work, acquisition and analysis of data, drafting and revising and approved the final version submitted.

\section{Author Disclosure}

Both authors declared no conflicts of interest.

\section{Funding Source}

This project was funded by the Department of Health under its program on Advancing Evidence-Assisted Decisions with Health Policy and Systems Research (AHEAD-HPSR) through the Philippine Council for Health and Research Development, and in coordination with the National Institutes of Health, University of the Philippines Manila.

\section{REFERENCES}

1. World Health Organization [Internet]. Geneva: WHO; c2021 [cited $2021 \mathrm{Apr}$. Overview; [about 1 screen]. Available from: https://www. who.int/health-topics/road-safety\#tab=tab_1.

2. World Health Organization. Global Status Report on Road Safety 2018 [Internet]. Geneva: World Health Organization; 2018 [cited 2021 Jun]. Available from: https://www.who.int/publications/i/ item/9789241565684

3. World Health Organization. Global Status Report on Road Safety 2013 [Internet]. Geneva:World Health Organization; 2013 [cited 2021 Jun]. Available from: https://apps.who.int/iris/handle/10665/78256.

4. Mace SE, Mayer TA. Triage. In: Baren JM, Rothrock SG, Brennan JA, Brown L, editors. Pediatric Emergency Medicine. Philadelphia: Saunders; 2008. p. 1087.

5. Wisner DH. History and current status of trauma scoring systems. Arch Surg. 1992 Jan; 127(1):111-7.

6. Loftis KL, Price J, Gillich PJ. Evolution of the Abbreviated Injury Scale: 1990-2015. Traffic Inj Prev. 2018; 19(Supp 2):S109-S113.

7. Reynolds P, Scattoloni JA, Ehrlich P, Cladis FP, Davis PJ. Anesthesia for Pediatric Trauma Patient. In: Davis PJ, Cladis FP, Motoyama EK, editors. Smith's Anesthesia for Infant and Children. Missouri: Mosby; 2011. p. 972-6.

8. Champion HR, Sacco WJ, Copes WS, Gann DS, Gennarelli TA, Flanagan ME. A revision of the Trauma Score. J Trauma. 1989 May; 29(5):623-9.

9. Domingues CA, Coimbra R, Poggetti RS, Nogueira LS, de Sousa RMC. New Trauma and Injury Severity Score (TRISS) adjustments for survival prediction. World J Emerg Surg. 2018 Mar 6; 13:12.

10. Kobusingye OC, Lett RR. Hospital-based trauma registries in Uganda. J Trauma. 2000 Mar; 48(3):498-502. 
11. Manoochehry S, Vafabin M, Bitaraf S, Amiri A. A comparison between the ability of revised trauma score and kampala trauma score in predicting mortality; a meta-analysis. Arch Acad Emerg Med. 2019 Jan 15; 7(1):e6. PubMed PMID: 30847441.

12. Feldhaus I, Carvalho M, Waiz G, Igu J, Matthay Z, Dicker R, et al. The feasibility, appropriateness, and applicability of trauma scoring systems in low and middle-income countries: a systematic review. Trauma Surg Acute Care Open. 2020 May 6; 5(1):e000424. PubMed PMID: 32420451.

13. Mukonkole SN, Hunter L, Möller A, McCaul M, Lahri S, Van Hoving DJ. A comparison of trauma scoring systems for injuries presenting to a district-level urban public hospital in Western Cape. S Afr J Surg. 2020 Mar; 58(1):37-42.

14. Roy N, Gerdin M, Schneider E, Kizhakke Veetil DK, Khajanchi M, Kumar V, et al. Validation of international trauma scoring systems in urban trauma centres in India. Injury. 2016 Nov; 47(11):2459-64.

15. Hung YW, He H, Mehmood A, Botchey I, Saidi H, Hyder AA, et al. Exploring injury severity measures and in-hospital mortality: a multihospital study in Kenya. Injury. 2017 Oct; 48(10):2112-8.

16. Aspelund AL, Patel MQ, Kurland L, McCaul M, van Hoving DJ. Evaluating trauma scoring systems for patients presenting with gunshot injuries to a district-level urban public hospital in Cape Town, South Africa. Afr J Emerg Med. 2019 Dec; 9(4):193-6.

17. Laforga BM. Philippines still a lower-middle income economy World Bank [Internet]. Quezon City: BusinessWorld Publishing; c2021 [updated $2020 \mathrm{Jul} 3$; cited 2021 Oct]. Available from: https:// www.bworldonline.com/philippines-still-a-lower-middle-incomeeconomy-world-bank/.

18. Jeong JH, Park YJ, Kim DH, Kim TY, Kang C, Lee SH, et al. The new trauma score (NTS): a modification of the revised trauma score for better trauma mortality prediction. BMC Surg. 2017 Jul 3; 17(1):77. PubMed PMID: 28673278.

19. Singh J, Gupta G, Garg R, Gupta A. Evaluation of trauma and prediction of outcome using TRISS method. J Emerg Trauma Shock. 2011 Oct; 4(4):446-9.

20. MacLeod JBA, Kobusingye O, Frost C, Lett R, Kirya F, Shulman C. A Comparison of the Kampala Trauma Score (KTS) with the Revised Trauma Score (RTS), Injury Severity Score (ISS) and the TRISS Method in a Ugandan Trauma Registry. 2003 Dec;29:392-8.

21. Clarkson CA, Clarkson C, Rubiano AM, Borgaonkar M. A Comparison of the Kampala Trauma Score with the Revised Trauma Score in a Cohort of Colombian Trauma Patients. PAJTCCES. 2012; 1(3):146-9.

22. Hajian-Tilaki K. Receiver Operating Characteristic (ROC) Curve Analysis for Medical Diagnostic Test Evaluation. Caspian J Intern Med. 2013 Spring; 4(2):627-35.

23. Tesfay K, Assefa M, Zenebe D, Gebremicael M, Kebede G, Gebrekirstos H. Road traffic injured patients with severe GCS and organ injury had a poor prognosis: a retrospective cohort study. BMC Public Health. 2019 Jun 13; 19(1):749

24. Amorim RL, Oliveira LM, Malbouisson LM, Nagumo MM, Simoes M, Miranda L, et al. Prediction of Early TBI Mortality Using a Machine Learning Approach in a LMIC Population. Front Neurol. 2020 Jan 24; 10:1366.

25. Huang YT, Huang YH, Hsieh CH, Li CJ, Chiu IM. Comparison of Injury Severity Score, Glasgow Coma Scale, and Revised Trauma Score in predicting the mortality and prolonged ICU stay of traumatic young children: a cross-sectional retrospective study. Emerg Med Int. 2019 Dec 1; 2019:5453624. PubMed PMID: 31885926.

26. Zadravecz FJ, Tien L, Robertson-Dick BJ, Yuen TC, Twu NM, Churpek MM, et al. Comparison of mental-status scales for predicting mortality on the general wards. J Hosp Med. 2015 Oct; 10(10):658-63.

27. Nuttall AG, Paton KM, Kemp AM. To what extent are GCS and AVPU equivalent to each other when assessing the level of consciousness of children with head injury? A cross-sectional study of UK hospital admissions. BMJ Open. 2018 Nov 28; 8(11):e023216. PubMed PMID: 30498041.
28. Li C, Chen Y, Zheng Q, Wu W, Chen Z, Song L, et al. Relationship between systolic blood pressure and all-cause mortality: a prospective study in a cohort of Chinese adults. BMC Public Health. 2018 Jan 5; 18(1):107.

29. Shih CJ, Chen YT, Ou SM, Lin CH, Tarng DC; Taiwan Geriatric Kidney Disease (TGKD) Research Group. Observed blood pressure and mortality among people aged 65 years and older: a communitybased cohort study. J Am Med Dir Assoc. 2016 Jul 1; 17(7):654-62.

30. Keneally RJ, Szpisjak DF, Hoffmann PJ, Park EJ, Albergo MS. Vital signs and physiologic derangement in patients with thoracic trauma in Iraq and Afghanistan. Mil Med. 2017 Nov; 182(11):e1881-4.

31. Garrido D, Assioun JJ, Keshishyan A, Sanchez-Gonzalez MA, Goubran B. Respiratory rate variability as a prognostic factor in hospitalized patients transferred to the intensive care unit. Cureus. 2018 Jan 23; 10(1):e2100. PubMed PMID: 29581913.

32. Ljunggren M, Castrén M, Nordberg M, Kurland L. The association between vital signs and mortality in a retrospective cohort study of an unselected emergency department population. Scand J Trauma Resusc Emerg Med. 2016 Mar 3; 24:21.

33. Rechtman E, Curtin P, Navarro E, Nirenberg S, Horton MK. Vital signs assessed in initial clinical encounters predict COVID-19 mortality in an NYC hospital system. Sci Rep. 2020 Dec 9;10(1):21545. PubMed PMID: 33298991.

34. Rolfe S. The importance of respiratory rate monitoring. Br J Nurs. 2019 Apr 25;28(8):504-8.

35. Hadisaputra IH, Suwedagatha G, Mahadewa TG. Adjustment of Trauma and Injury Severity Score (TRISS) and Revised Trauma Score (RTS) in Predicting Mortality of Multitraumapatients in Sanglah Hospital Bali. Biomed Pharmacol J. 2021 Mar;14(1):267-72.

36. Egglestone R, Sparkes D, Dushianthan A. Prediction of mortality in critically-ill elderly trauma patients: a single centre retrospective observational study and comparison of the performance of trauma scores. Scand J Trauma Resusc. 2020 Sep 23;28:95.

37. Aoki M, Abe T, Saitoh D, Oshima K. Epidemiology, Patterns of treatment, and Mortality of Pediatric Trauma Patients in Japan. Sci Rep. 2019 Jan 29;9(1):917.

38. Puro SS, Shen S, Neyens DM. Factors Affecting Hospital Length of Stay for Drivers with Traumatic Brain Injuries from Motor Vehicle Crashes. Transp Res Rec. 2016;2601:84-9.

39. Li T, Yang YC, Anderson JJ. Mortality increase in late-middle and early-old age: heterogeneity in death processes as a new explanation. Demography. 2013 Oct;50(5):1563-91.

40. Kirshenbom D, Ben-Zaken Z, Albilya N, Niyibizi E, Bala M. Older Age, Comorbid Illnesses, and Injury Severity Affect Immediate Outcome in Elderly Trauma Patients. J Emerg Trauma Shock. 2017 Jul-Sep;10(3):146-50.

41. McLaughlin C, Zagory JA, Fenlon M, Park C, Lane CJ, Meeker D, et al. Timing of mortality in pediatric trauma patients: A National Trauma Data Bank analysis. J Pediatr Surg. 2018 Feb;53(2):344-51.

42. Sayyed Hoseinian SH, Ebrahimzadeh MH, Peivandi MT, Bagheri F, Hasani J, Golshan S, et al. Injury Patterns among Motorcyclist Trauma Patients: A Cross Sectional Study on 4200 Patients. Arch Bone Jt Surg. 2019 Jul;7(4):367-72.

43. Oyeniyi BT, Fox EE, Scerbo M, Tomasek JS, Wade CE, Holcomb JB. Trends in 1029 trauma deaths at a level 1 trauma center: Impact of a bleeding control bundle of care. Injury. 2017 Jan;48(1):5-12.

44. Alvarez BD, Razente DM, Lacerda DA, Lother NS, VON-Bahten LC, Stahlschmidt CM. Analysis of the Revised Trauma Score (RTS) in 200 victims of different trauma mechanisms. Rev Col Bras Cir. 2016 Sep-Oct;43(5):334-40.

45. Tang OY, Marqués CG, Ndebwanimana V, Uwamahoro C, Uwamahoro D, Lipsman ZW, et al. Performance of Prognostication Scores for Mortality in Injured Patients in Rwanda. West J Emerg Med. 2021 Jan 22;22(2):435-44. 